\title{
O design e a comunicação afetiva no âmbito das lojas conceito: identidade, envolvimento e analogia entre as marcas e a sociedade de consumo atual Design and affective communication in the context of concept stores: identity, involvement and analogy between trademarks and current consumer society
}

\author{
Celeste Maldonado Alves Teixeira \& Claudia Rocha Mourthé
}

lojas conceito, interiores, design emocional, prazer, sociedade

\begin{abstract}
O presente artigo aborda o caráter comunicacional/informativo, afetivo e emocional estabelecidos nos espaços interiores comerciais, trazendo os mesmos para o atual contexto social dentro da temática das Lojas Conceito, sob o ponto de vista do design de interiores e das experiências geradas nesses ambientes. Confirma-se, através da relação entre os prazeres estabelecidos dentro do espaço e o que hoje é entregue ao público em termos de lojas, a relevância destes espaços e como seus mais variados estímulos são identificados e aplicados com a finalidade de tocar o emocional e despertar sensações. Busca-se com este artigo, reafirmar a importância deste segmento de loja como uma ferramenta de comunicação, um recurso que as marcas se utilizam para informar aos clientes e à sociedade sobre seus produtos, sua filosofia e seus valores. Envolvendo e estimulando sentidos através de ambientes de trocas de experiências, as lojas conceito criam no usuário um maior reconhecimento e entendimento das qualidades e características de uma marca, criando vínculos e aguçando o desejo de compra.
\end{abstract}

concept stores, interiors, emotional design, pleasure, society

The present article deals with the communicational / informative, affective and emotional character established in the commercial interior spaces, bringing them to the current social context within the theme of the Concept Stores, from the point of view of interior design and the experiences generated in these environments. It is confirmed, through the relationship between the pleasures established within space and what is now given to the public in terms of stores, the relevance of these spaces and how their various stimuli are identified and applied for the purpose of touching the emotional and awakening sensations. This article seeks to reaffirm the importance of this store segment as a communication tool, a resource that brands use to inform customers and society about their products, their philosophy and their values. By engaging and stimulating senses through exchange experiences environments, concept stores create in the user a greater recognition and understanding of the qualities and characteristics of a brand, creating bonds and sharpening the desire to buy.

\section{Introdução}

As Lojas Conceito ou Flagship Stores, atuam como um forte e importante ponto de contato, com recursos que estimulam os sentidos, sendo um veículo transmissor de mensagens e aproximando o cliente/consumidor das marcas. Tratam-se de lojas diferenciadas e com ambientações estratégicas, com o objetivo de levar até o cliente uma experiência da marca e configuram uma forte tendência do mercado contemporâneo. O relacionamento que essas lojas estabelecem com os clientes geram maior receptividade com o público. "A atmosfera é o esforço de desenhar um ambiente de compra que produza efeitos emocionais no indivíduo de modo que aumente sua probabilidade de compra" (Kotler, 1973, p. 50). Essa frase do autor endossa a capacidade do espaço interior atuar em conjunto com a marca visando atingir o emocional do consumidor, sendo este espaço uma ferramenta para o design.

O presente artigo analisa exemplos de Lojas Conceito no Rio de Janeiro e em São Paulo, enquanto correlaciona o design dos seus espaços internos com os conceitos do design emocional e afetivo, reafirmando a importância destas ideias no que tange à sua comunicação com o público consumidor e seu caráter informacional. O processo se inicia a partir do resgate

Anais do $9 \% \mathrm{CIDI}$ e 9 CONGIC

Luciane Maria Fadel, Carla Spinillo, Anderson Horta, Cristina Portugal (orgs.)

Sociedade Brasileira de Design da Informação - SBDI

Belo Horizonte | Brasil | 2019

ISBN 978-85-212-1728-2
Proceedings of the 9th CIDI and 9th CONGIC

Luciane Maria Fadel, Carla Spinillo, Anderson Horta, Cristina Portugal (orgs.)

Sociedade Brasileira de Design da Informação - SBDI

Belo Horizonte | Brazil | 2019

ISBN 978-85-212-1728-2 
Teixeira, C.M.A. \& Mourthé, C.R. | O design e a comunicação afetiva no âmbito das lojas conceito: identidade, envolvimento e analogia entre as marcas e a sociedade de consumo atual

desses conceitos, trazendo os mesmos para o contexto dos espaços físicos (lojas) da contemporaneidade e para os produtos que neles são comercializados, através da análise de imagens do interior de algumas lojas (coletadas na internet e de acervo pessoal) e a interação de seu público consumidor e visitantes.

Configurando-se como parte da elaboração da minha dissertação de mestrado, em andamento, este artigo tem como objetivo afirmar a importância das Lojas Conceito no cenário social atual, e como estes espaços e seus produtos são trabalhados para interagir e se conectar com o público consumidor, resultando em uma aproximação do cliente com a marca e suas diferentes formas de aguçar e despertar sensações e sentimentos. Objetiva-se assim um levantamento reflexivo sobre o tema, validando este modelo de loja no que tange a sua diferenciação e vínculo, sendo a mesma um canal condutor de informações e sensações, transformando conceitos do design em elementos tangíveis e proporcionando prazer, conhecimento e informação através das interações entre o espaço projetado e o usuário.

\section{As lojas conceito e o despertar do desejo de consumo na sociedade atual}

No Brasil, as Lojas Conceito ainda são vistas como novidade. São lojas em que a participação e o envolvimento do consumidor/usuário são fundamentais durante a experiência de compra ou visitação à loja. Essa aproximação entre marca e consumidor garante um maior poder de comunicação direta entre ambos e, para o consumidor contemporâneo que deseja satisfazer não só suas necessidades, mas também seus desejos, é caracterizado como um importante diferencial competitivo. Daniel Raposo (Raposo, 2010) destaca em seu pensamento no campo do design de produto, que deve existir sempre uma comunicação entre marca e usuário, cuja experiência dessa relação deve ser a mais diferenciada e a melhor possível. Exatamente assim também ocorre nos ambientes interiores, onde marcas contemporâneas estão inseridas na responsabilidade de saciar a necessidade de informação, contexto em que as empresas devem se adaptar ao cliente, sendo o consumidor decisivo na aprovação. Em muitos casos, essa aproximação se dá literalmente, tornando os produtos mais acessíveis ao consumidor e trazendo-os para o seu campo de visão, para o alcance das suas mãos. O cliente passa a ter uma liberdade no toque, na escolha, na comparação, passa a ser permitido uma intimidade maior com o que se pretende adquirir, sentir o seu peso, sua textura, seu odor, e que ali naquele primeiro contato, já se estabeleça uma relação. Os produtos deixam de estar afastados, atrás de um balcão cuja ultrapassagem é proibida ou dispostos em estantes altas e inacessíveis cujo permitido apenas era olhar de longe (Figura 1 e Figura 2).

Figura 1 e 2: Loja conceito Le Postiche Barra Shopping (Fonte: Divulgação da empresa, portal Nova Varejo http://www.portalnovarejo.com.br. Acesso em mar. de 2019).
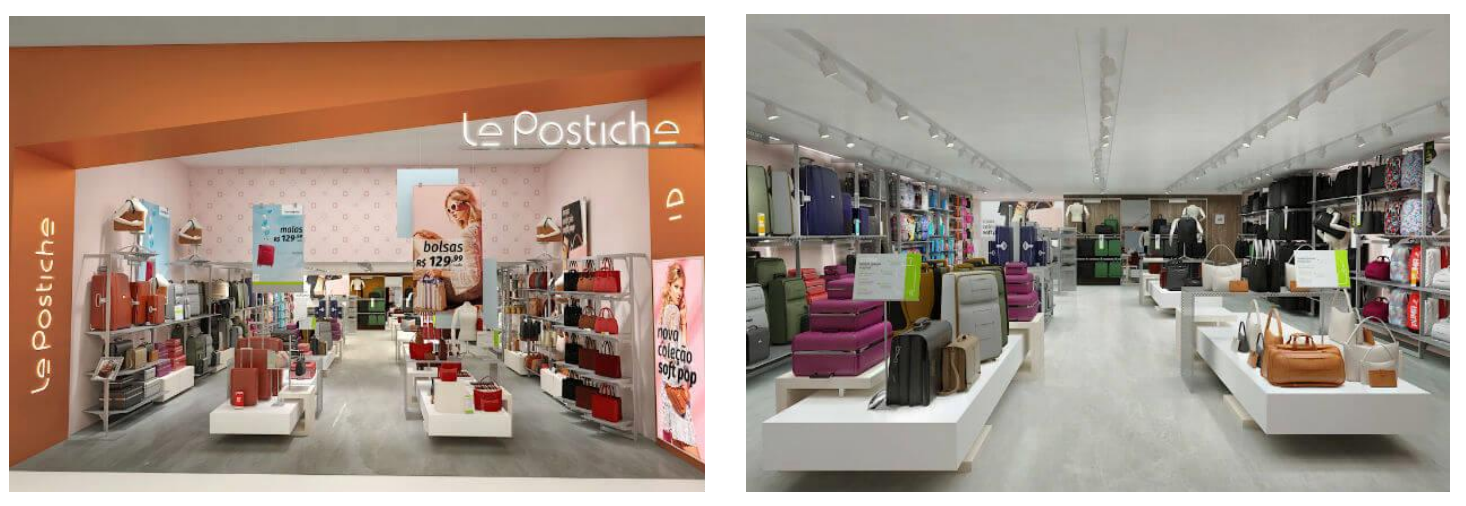

A neurociência afirma que experiências satisfatórias são compreendidas imediatamente pelo cérebro, registrando e positivando a mesma de imediato e ativando a memória afetiva sempre que for solicitada, ou seja, sempre que o usuário precisar de algo relativo àquela marca ou determinado produto, sua memória afetiva será acessada resgatando em um primeiro momento 
Teixeira, C.M.A. \& Mourthé, C.R. | O design e a comunicação afetiva no âmbito das lojas conceito: identidade, envolvimento e analogia entre as marcas e a sociedade de consumo atual

a experiência positiva vivenciada em determinado ambiente. O neurocientista António Damásio, considerado um dos pais das teorias sobre o "cérebro emocional" e citado com frequência pelos pesquisadores do campo do Design e Emoção, afirma que ao fazermos escolhas, tendemos a imaginar e avaliar futuras consequências das opções que fazemos bem como suas vantagens e desvantagens. Quando uma opção provoca uma sensação desagradável, tendemos a eliminá-la; ao contrário, quando a opção provoca uma sensação agradável, tendemos a considerá-la. (Damásio, 1996).

Diferente das lojas tradicionais que tem como objetivo principal a venda e o lucro, as Lojas Conceito possuem o objetivo maior de criar um vínculo que aproxime o cliente da marca. $O$ estimulo dos sentidos é a forma mais recorrente de gerar estas experiências, que toca grande parte dos consumidores. São lojas que deixam para um segundo momento o objetivo de venda, para ter como objetivo primário uma conexão com o cliente. Justamente nesse tipo de interação proporcionada por estas lojas em específico, é que ocorre a criação de um sentido para a compra, e a partir daí o consumidor tem a sua tomada de decisão entre uma marca ou outra. Em uma experiência de consumo em uma Loja Conceito, para maior fixação da mensagem que a marca deseja transmitir, os sentimentos humanos são despertados e utilizados como ativadores das sensações. Podemos ver isso nas imagens da Loja Conceito da Ri Happy do Rio de Janeiro (Figura 3). O interior da loja é um passeio pela cidade do RJ, o que faz com que as crianças conheçam um pouquinho da cidade enquanto brincam ou escolhem seus brinquedos. São utilizados apelos visuais que resgatam lembranças, além de muitos brinquedos e jogos estarem disponíveis para uso a qualquer momento, inclusive jogos da infância de muitos adultos e uma carruagem de princesa dos contos de fadas para as crianças, trabalhando o emocional e o afetivo dos clientes no resgate de lembranças e na criação de um vínculo com este espaço.

Figura 3: Loja conceito Ri Happy, Rio de Janeiro (Fonte: Divulgação da empresa, https://diariodorio.com/rio-de-janeirorecebe-sua-primeira-loja-conceito-de-brinquedos/. Acesso em mar. de 2019).

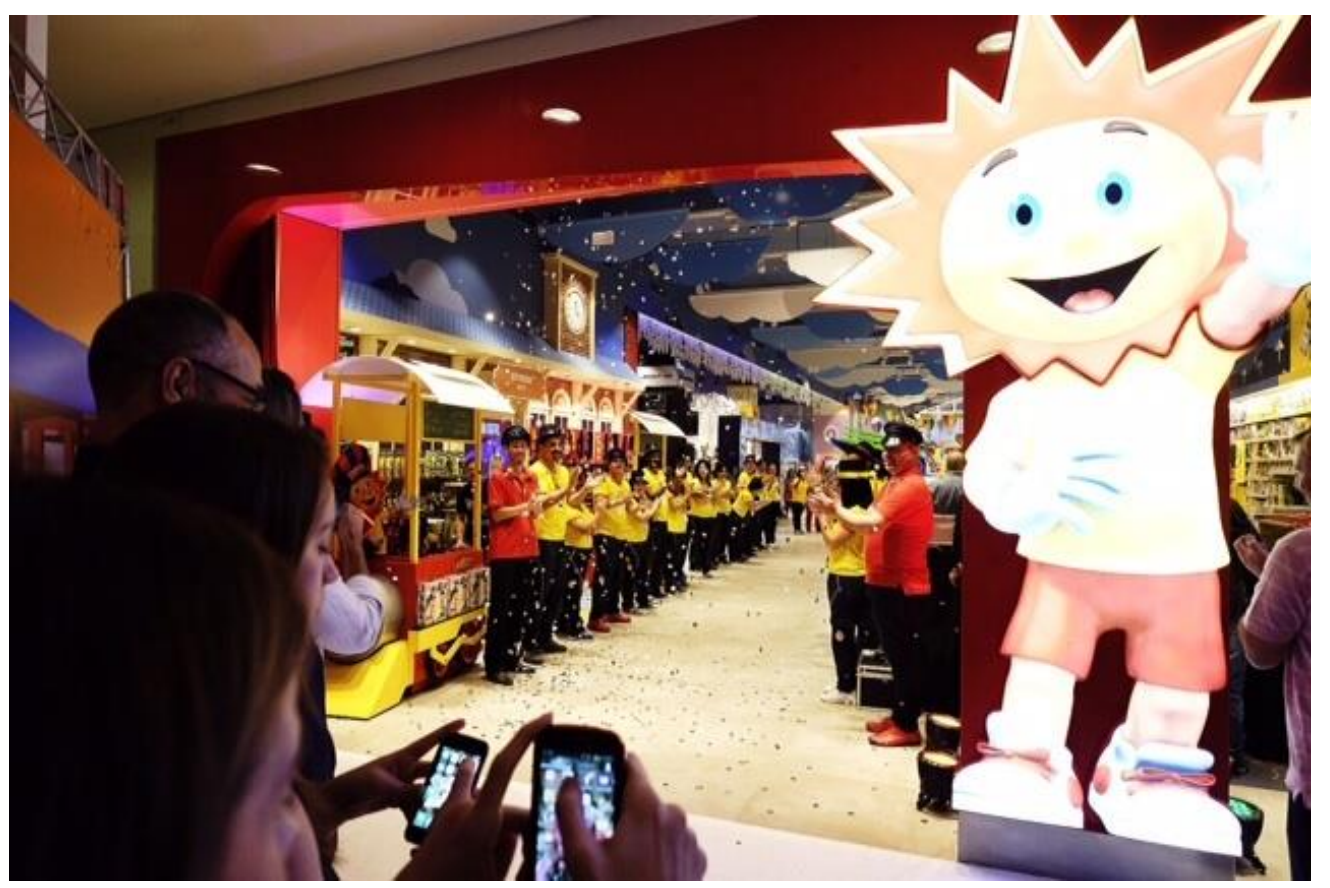

O momento atual da sociedade revela que os espaços estão se tornando, cada vez mais, parte de uma experiência de consumo e as lojas conceito são vistas como instrumento para seduzir, envolver, informar e fidelizar. O ambiente é projetado como parte integrante deste processo, gerando através das potencialidades do design e seu poder de comunicação, uma ligação afetiva com o público, fazendo, muitas vezes, com que o público se utilize disso para se destacar em seu grupo de convívio. Isso pode ser comprovado através do crescente número dos espaços comerciais que criam cenários em suas lojas para que o seu público-alvo tire "selfies" ou se deixem fotografar por outra pessoa e publiquem nas redes sociais, deixando 
Teixeira, C.M.A. \& Mourthé, C.R. | O design e a comunicação afetiva no âmbito das lojas conceito: identidade, envolvimento e analogia entre as marcas e a sociedade de consumo atual

claro a sua preferência e identificação com determinado lugar. São diversas lojas no Brasil e no mundo que já projetam seus espaços pensando num melhor ambiente para as fotos que seus clientes irão fazer (Figura 4), divulgando o espaço na mídia enquanto o cliente valida aquela experiência e se afirma em um determinado grupo ao utilizar aquele espaço e aquele produto.

Figura 4: Marcação de pessoas nos perfis oficiais do Espaço Havaianas Rio e da Galeria Melissa SP (Fonte: instagram/melissaoficial e instagram/havaianas. Acesso em abr. de 2019).

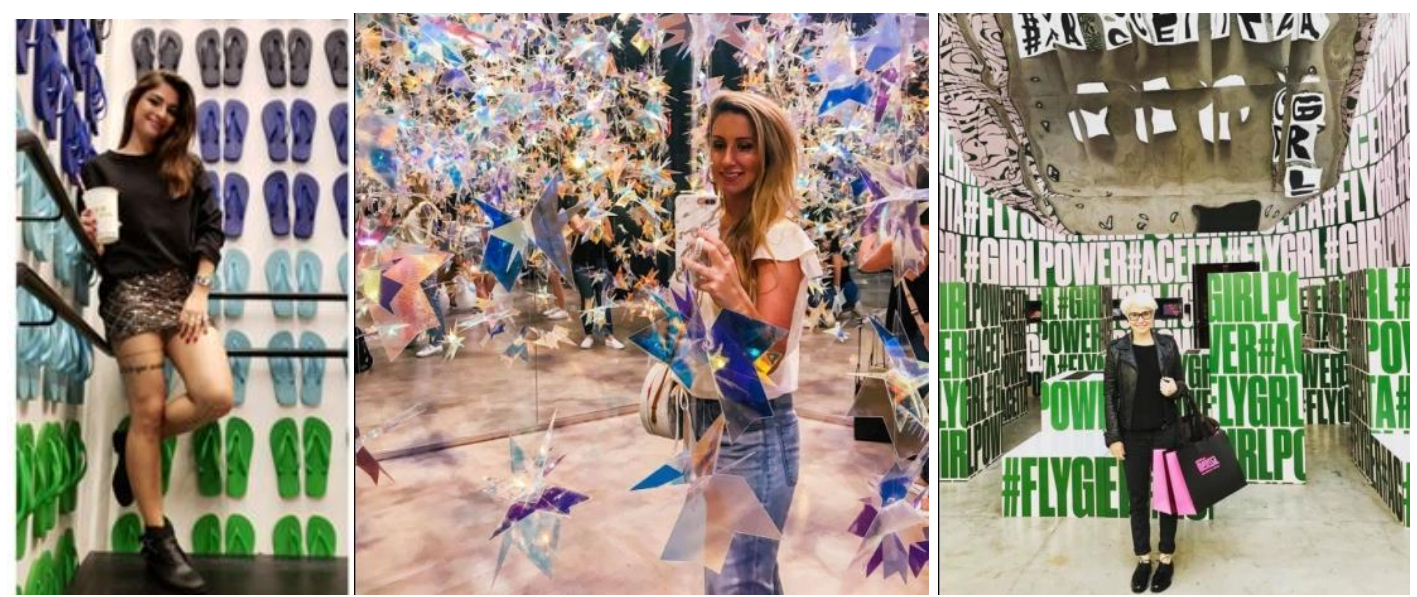

Assim como a ideia de Kotler (1973), que diz sobre a capacidade do espaço e sua atmosfera produzir efeitos no indivíduo e aumentar a probabilidade de compra, tal conceito de atmosfera tem o objetivo de representar qualidades sensoriais em destaque no espaço interior, que são projetadas intencionalmente para provocar respostas específicas no público-alvo. Assim, os espaços comerciais conseguem gerar uma diferenciação no mercado, se destacando dos demais do mesmo seguimento e em paralelo, reforçar as percepções do cliente sobre determinado produto ou qualidade do serviço no ambiente em que se encontra.

A ambiência do espaço comercial é o condutor que leva percepções da marca até o usuário e o design de seus interiores e a forma como foram projetados traduz muito a essência da marca que representa. Podem traduzir um estilo de vida, um estado de espírito, nível social e junto com materiais empregados por exemplo, provocam sensações, emoções e percepções em seus usuários, selecionando assim o público específico do negócio, afinal, "a arquitetura de interiores pode ser utilizada para selecionar clientes de forma indireta" (GURGEL, 2010, p.15). Pegando como exemplo, neste caso, as Lojas Conceito da Granado (Figura 5), é visível a representação de uma época do passado, mas especificamente na década de 1920, onde surgiu a primeira loja do grupo no Centro do Rio de Janeiro. O projeto de interiores da loja promove um resgate do tempo passado e o resultado final é um convite ao público para voltar no tempo e tentar vivenciar como eram e como funcionavam as farmácias e perfumarias deste período. Um resgate da tradição destes espaços e a tentativa de trazer consigo a aura desta época, o antigo no novo, através do resgate do mobiliário original, dos frascos, ladrilho dos pisos, a presença forte do vidro tanto nas prateleiras quanto nas embalagens, etc. 
Teixeira, C.M.A. \& Mourthé, C.R. | O design e a comunicação afetiva no âmbito das lojas conceito: identidade, envolvimento e analogia entre as marcas e a sociedade de consumo atual

Figura 5: Loja conceito Casa Granado - Centro do RJ (Fonte: www.granado.com.br. Acesso em mar. de 2019).

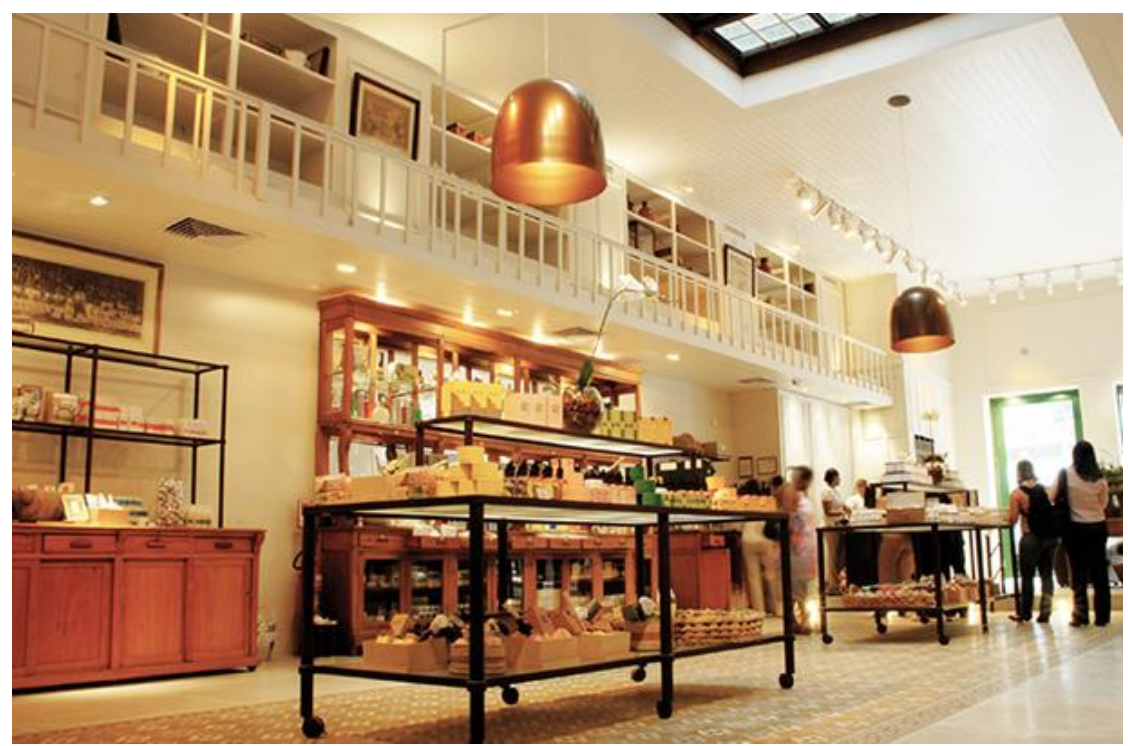

\section{Design emocional e o vínculo afetivo nas lojas conceito}

A área denominada Design e Emoção surgiu em 2003, anunciada pelo professor e pesquisador Aren Kurtgözü. Esta também se popularizou pelos nomes de Design Emocional e Design Afetivo e tinha como objetivo o conhecimento e compreensão das respostas emocionais evocadas pelos objetos, e que neste artigo adaptamos e trazemos para o mundo do design de interiores, uma vez que os espaços interiores também são "consumidos" pelos seus usuários. Donald Norman em seu livro: Design Emocional - Por que Adoramos (ou Detestamos) os Objetos do Dia-a-dia (2003) refina a definição de Design Emocional delineando os três níveis de impacto emocional que agem sobre as pessoas quando interagem com produtos (Figura 6). Os níveis Visceral (no campo na psicologia, no subconsciente), Comportamental (o que cada interação produz, incluindo acessibilidade) e Reflexivo (a decisão pessoal, a compreensão de cada pessoa) são conceitos validados tanto por pesquisadores quanto pela reação do mercado.

Figura 6: Os 3 níveis do Design Emocional. (Fonte: Design Emocional - Por que Adoramos (ou Detestamos) os Objetos do Dia-a-dia. Donald Norman, 2003).

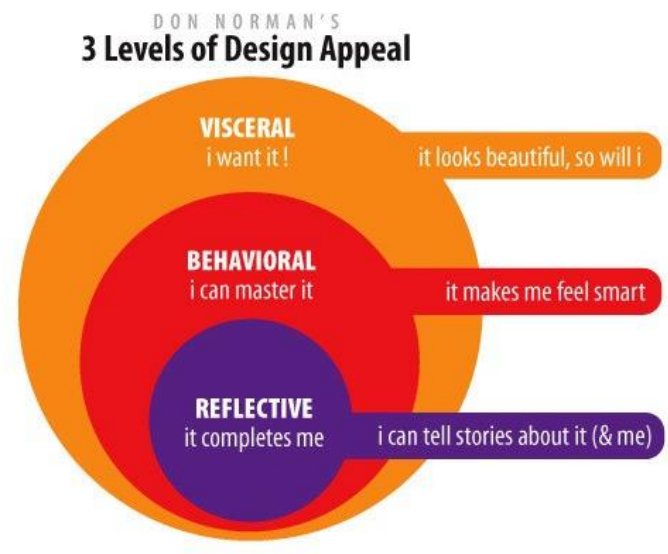


Teixeira, C.M.A. \& Mourthé, C.R. | O design e a comunicação afetiva no âmbito das lojas conceito: identidade, envolvimento e analogia entre as marcas e a sociedade de consumo atual

Além dos aspectos estéticos e funcionais, todos os produtos de Design devem incluir os aspectos emocionais, uma vez que desencadeiam a emoção em suas mais variadas formas de apresentação no usuário. O espaço interior é um produto de Design bem como um objeto e uma marca por exemplo. Ambientes mexem com os sentidos e por sua vez com o emocional. Diversas sensações e emoções podem ser vivenciadas dentro de um ambiente como alegria, desgosto, nostalgia, satisfação, decepção. Como bem observa o designer argentino Jorge Frascara (2004), "há design para tornar a vida possível, design para tornar a vida mais fácil e design para tornar a vida mais prazerosa". Também é de sua autoria a seguinte afirmação: "Todos os dias, desde o momento em que toca o despertador até o dia seguinte, todas as nossas atividades são facilitadas ou obstruídas pelo design, seja este gráfico, industrial ou de ambiente".

Muito além dos seus limites físicos, o ambiente comercial transpassa pisos, paredes e tetos, e assume um caráter comunicacional, com troca de sensações, emoções e desejos, sob a ótica do Design Emocional. É no interior do ambiente, cercado por estas sensações estimuladas pelo espaço, que o cliente compreende os valores de uma determinada marca e vivencia uma experiência de consumo. O design de interiores aplicado a um projeto comercial, deve traduzir fielmente a imagem da empresa que representa, valorizando conceitos inerentes aos produtos e serviços oferecidos (Gurgel, 2010). Nas Lojas Conceito, estes serviços geralmente são diferenciados, existe a liberdade de oferecer serviços e produtos que só existam nesta loja, como uma espécie de teste com o consumidor. Tendo o teste dado certo, a marca escolhe se quer colocar o produto em todas as lojas da rede ou não. Esses espaços servem também para aprimorar e desenvolver melhor os produtos de uma marca enquanto os mesmos são consumidos, como na Loja Conceito da Kopenhagen (Figura 7), que além dos chocolates, servem diversos tipos de cafés e bebidas similares, o aroma de chocolate é constante em todo o ambiente e uma voz eletrônica é acionada automaticamente quando o cliente se aproxima de uma prateleira específica. Um ambiente aconchegante e com livre circulação, propício ao consumo.

Figura 7: Loja Conceito Kopenhagen, São Paulo. (Fonte: https://www.infomoney.com.br/franquias/noticia/2961304/paracomemorar-anos-kopenhagen-investe-milhoes-loja-conceito. Acesso em abr. de 2019).

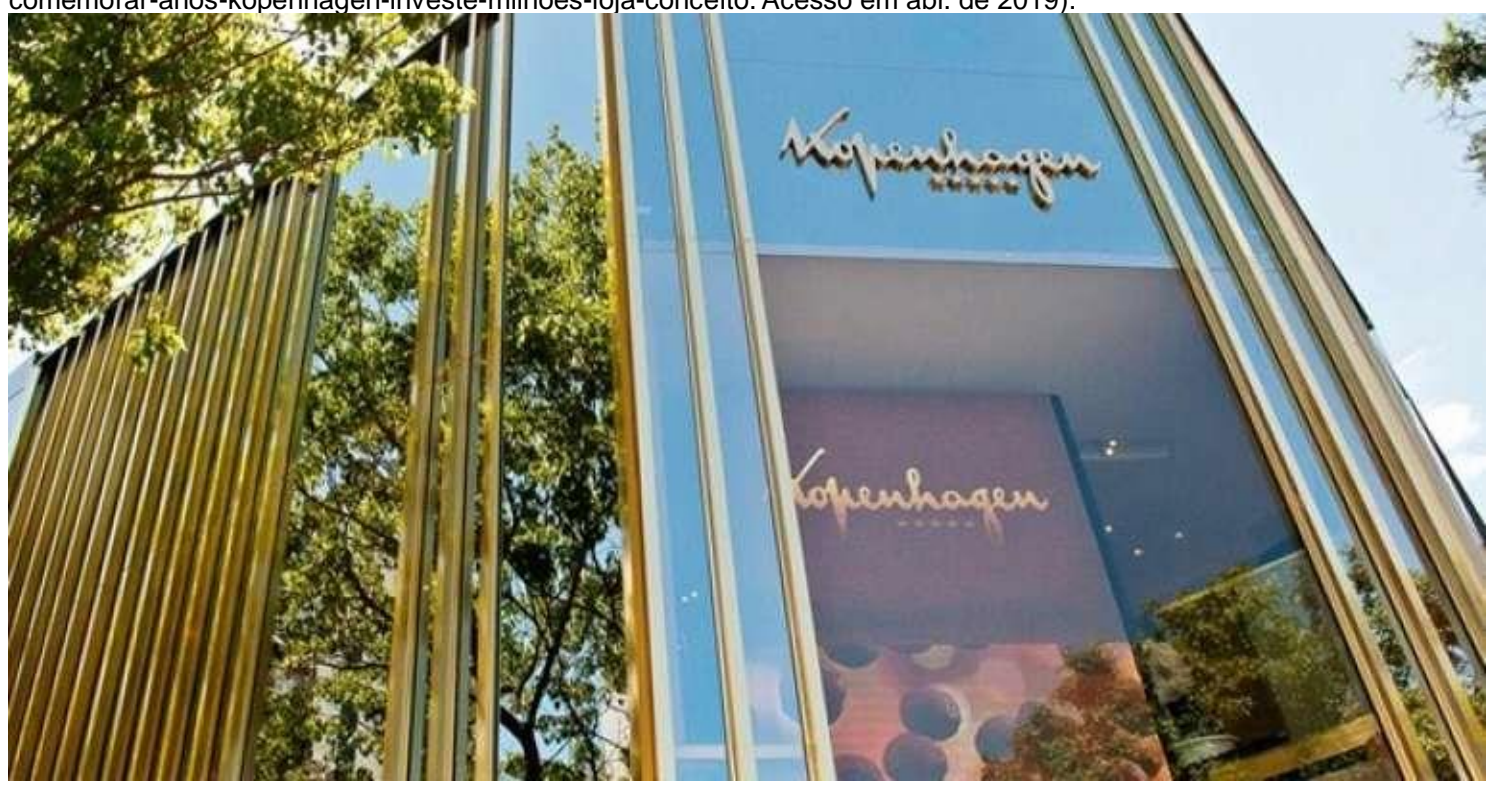

Mais do que um local onde se vai apenas para consumir um produto quando se precisa, os novos modelos de espaços comerciais fundamentados no design emocional e na experiência do usuário colocam o ato de vender em segundo plano, enaltecendo o atendimento e o vínculo com o cliente como o primeiro degrau para a satisfação e a fidelização. O lucro e a venda deixam de ser importantes em um primeiro momento, pois sabem que, com o envolvimento do cliente no universo da marca, a venda será garantida no final ou até mesmo em outro momento, em uma outra loja da marca. As lojas conceito deixam de ser uma loja com foco em venda para serem uma loja com foco em experiência, funcionando como um laboratório da 
Teixeira, C.M.A. \& Mourthé, C.R. | O design e a comunicação afetiva no âmbito das lojas conceito: identidade, envolvimento e analogia entre as marcas e a sociedade de consumo atual

marca onde o contato com o cliente abre diversas possibilidades de relacionamento, melhorias e um retorno direto sobre como a marca e seus produtos estão sendo vistos pelo consumidor.

\section{Ativação dos sentidos e o despertar do prazer}

O Design Emocional, quando bem aplicado, tem o poder de criar vínculos e tornar as marcas ainda mais desejadas através das experiências sentidas pelos usuários do espaço. É a conexão de todos os cinco sentidos, a capacidade de provocar emoções e relembrar as sensações esquecidas. O foco é uma relação duradoura com o intuito de fidelizar através de experiências.

Proporcionar experiências agradáveis que geram sensações envolvem os sentidos, que são ativados através de elementos primordiais para a construção de um bom espaço comercial: materiais, texturas, iluminação, som e odores. O consumir contemporâneo se dá muito além de apenas um produto exposto em uma prateleira e as Lojas Conceito se utilizam disso para explorar o Design Emocional em sua ambiência e se adequar aos novos tempos onde o consumidor é muito mais exigente. É preciso "falar mais ao coração do que a mente" (Kotler, 2003, p. 90)

Para o designer e consultor Patrick Jordan (2001), o conceito de agradabilidade, associada ao prazer, deve sempre estar presente, desencadeando emoções positivas no usuário. Emoções estão diretamente ligadas aos sentimentos e ao prazer. Comumente nos deparamos com determinados espaços comerciais que fazemos questão de frequentar mesmo sem estarmos precisando consumir nada. Frequentamos porque nos sentimos bem ali, porque algo neste espaço nos toca diretamente, porque o produto reflete nosso estilo de vida, porque o espaço nos convida a ficar e até perder a noção do tempo tamanho a forma como ele nos atende. Podem existir muitos outros lugares com os mesmos produtos, mas sempre um será diferente. Como já dito anteriormente, experiências satisfatórias viram memórias afetivas, que são acessadas resgatando a experiência positiva vivenciada no ambiente.

No que tange ao crescente número de Lojas Conceito e suas características, a grande questão a ser compreendida é como se dá a conexão emocional entre a marca e o usuário nestes espaços. As relações afetivas que se desdobram em decorrência da interação dos espaços com o usuário, favorecem uma atmosfera de aproximação e encantamento, "algo a ser visto e lembrado, um conjunto de elementos do qual esperamos que nos dê prazer" (Lynch, 1960). Jordan cita em sua obra, a Estrutura dos 4 Prazeres, criada pelo antropólogo Lionel Tiger (citado por JORDAN, 2001), a qual podemos incorporar no campo do Design de Interiores e com ela compreender melhor as diferentes fontes de prazer relacionadas ao espaço e seus usuários. O autor cita que as fontes de prazer oriundas das emoções e dos sentimentos podem ser: fisiológicas, psicológicas, sociais e ideológicas.

A questão mais trabalhada no campo do Design Emocional é a relação emocional entre os seres humanos e o design de um produto ou, no caso deste artigo, de um ambiente comercial. Como defendido por Jordan (Jordan, 2001), o processo emocional se origina de um prazer maior gerado por estados e relações de troca com o meio, sendo primordial para a interação entre o consumidor e ambiente comercial. Um diagrama apresenta a estrutura dos 4 prazeres (Figura 8), tendo alguns fatores elementares do design como antecessores para a chegada nessa estrutura. Partimos da premissa do processo criativo no design que é a forma e a função como $1^{\circ}$ e $2^{\circ}$ fator, temos um $3^{\circ}$ fator que é o sentimento e que, até algum tempo atrás, não era tomado como prioridade e temos o prazer oriundo destes 3 fatores como um resultado e um benefício. Logo, tendo o prazer como resultado, somos conduzidos a analisar a estrutura dos 4 prazeres básicos da experiência humana que nos leva a esclarecimentos importantíssimos sobre o desencadeamento destes espaços comerciais e sua importante contribuição. 
Teixeira, C.M.A. \& Mourthé, C.R.| O design e a comunicação afetiva no âmbito das lojas conceito: identidade, envolvimento e analogia entre as marcas e a sociedade de consumo atual

Figura 8: Diagrama da Estrutura dos 4 prazeres. Fonte: a autora.

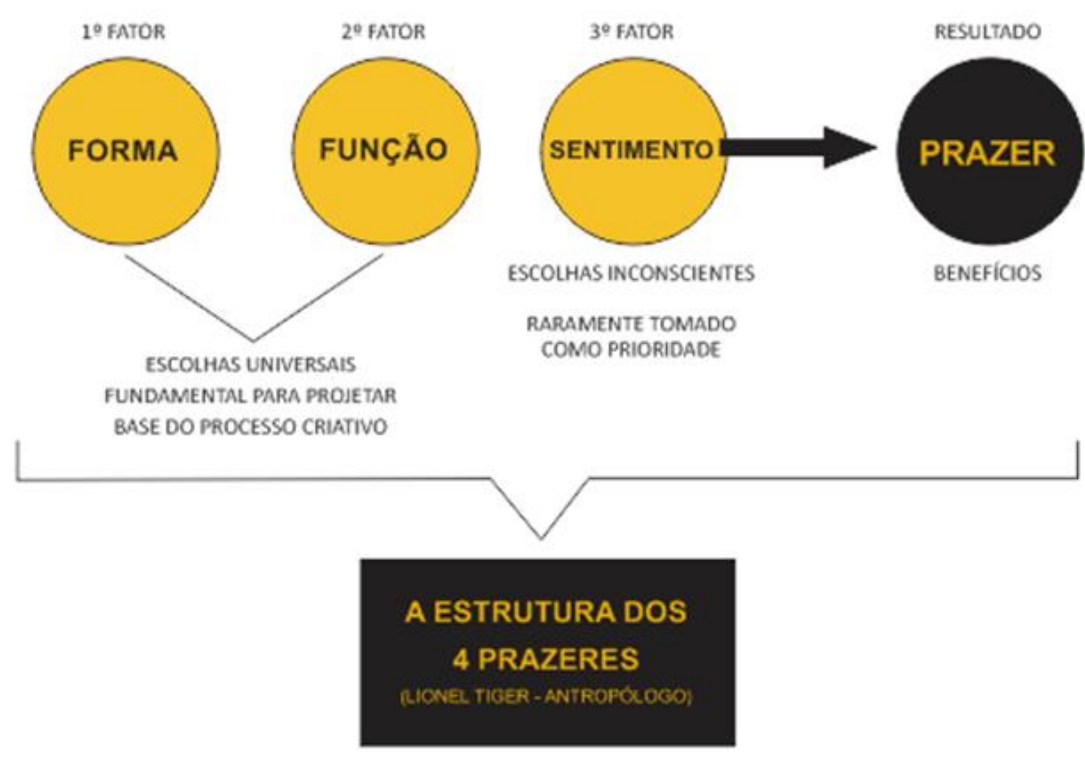

A Estrutura dos Quatro Prazeres, elaborada pelo antropólogo Lionel Tiger (in Jordan 2000), que podem ser:
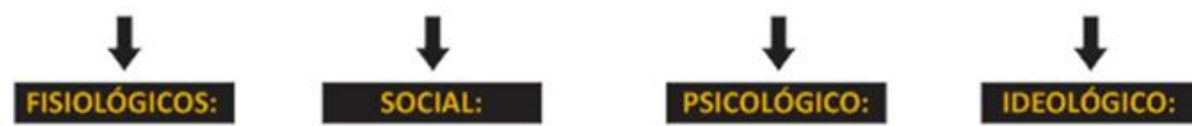

Ao se utilizar um produto ou apenas ao adquiri-lo, estamos adquirindo também uma série de benefícios emocionais que são convertidos em uma forma de prazer. Esse caráter singular da experiência emocional humana merece ser destacado. A interpretação da experiência determina a emoção que se atinge num determinado momento. A experiência emocional humana, no que tange ao prazer em vivenciar certas situações, merece ser destacada e daí seu enquadramento em um dos 4 tipos de prazeres abaixo:

- Prazer Fisiológico: Derivado dos sentidos humanos. Tato, visão, olfato, paladar e audição. Um ambiente bem projetado, com cores agradáveis, com um cheiro característico e marcante por exemplo.

- Prazer Social: Relacionado aos contatos, à imagem pessoal e ao status. Tem como exemplo a exibição de fotos em determinados restaurantes nas redes sociais, em grupos sociais específicos. Favorece uma afirmação de classe social e uma diferenciação dos demais. Também faz parte encontrar os amigos em um determinado lugar que acaba virando uma espécie de "point" dos amigos.

- Prazer Psicológico: Relacionado às reações emocionais e cognitivas das pessoas. Uma reação de encantamento, identificação, resgate de uma memória afetiva, sensação de bem-estar e pertencimento à determinado lugar.

- Prazer Ideológico: Relativo ao conjunto de crenças e valores, incluindo valores morais e aspirações pessoais. Inclui os prazeres advindos de livros, arte e música. Frequentar espaços que se preocupam com meio-ambiente por exemplo, que se utilizam de materiais reciclados em sua ambientação, que comercializam produtos amigos do meio ambiente, restaurantes veganos, etc. Tais prazeres surgem pelo apoio à determinadas causas e a responsabilidade social e moral.

A Estrutura dos 4 Prazeres contribui grandiosamente para o campo do Design Emocional e para a compreensão de como o design pode despertar prazer nas pessoas. Os estudos de Jordan podem ser facilmente convertidos para espaços interiores, onde os frequentadores do 
Teixeira, C.M.A. \& Mourthé, C.R. | O design e a comunicação afetiva no âmbito das lojas conceito: identidade, envolvimento e analogia entre as marcas e a sociedade de consumo atual

espaço comercial por exemplo, projetam e atribuem características nestes espaços, nos permitindo obter respostas investigáveis de acordo com a forma que cada pessoa reage ao que 0 ambiente Ihe transmite, a como esta pessoa se comporta, o efeito que o ambiente causa nela e como o ambiente fica marcado para o público-alvo.

\section{Resultados Conclusivos}

Por ser um campo ainda considerado bastante recente e ainda com poucos estudos, as marcas estão se aproveitando deste fato para investirem em seus ambientes físicos focando na interação do homem com o espaço na busca de respostas emocionais, criação de vínculo, comunicação, favoritismo e vantagem competitiva. Visto isso, é possível concluir que uma marca que instiga o emocional e as sensações em seu espaço comercial é capaz de gerar valores essenciais que as diferenciam dos concorrentes. Os espaços interiores das Lojas Conceito são fruto de um processo intencional que afeta diretamente os usuários do espaço e suas atitudes, sendo as emoções influenciadoras e assumindo assim um papel fundamental neste processo.

Como conclusão sobre o presente tema após levantamento de referenciais bibliográficos sobre $o$ assunto e observação dos espaços, temos a afirmação da importância e a validação deste modelo de loja no que tange a sua diferenciação e vínculo estabelecido pela mesma com o cliente e suas formas de despertar e aguçar sentimentos. Fica evidente como o comportamento do usuário no interior das Lojas Conceito em resposta a determinados estímulos sensoriais geram diferentes tipos de prazeres e em consequência uma relação emocional com a marca e ainda altera a maneira como a mesma se relaciona com o cliente através desse estilo de loja em específico.

As análises realizadas no presente artigo, confirmam que as experienciais vivenciadas no interior de uma loja conceito, são realmente passíveis de um vínculo emocional com o cliente e uma maior aproximação com a marca e seus produtos, culminando para o despertar do desejo de compra e validando o surgimento cada vez maior de Lojas Conceito no país nos últimos 10 anos e o investimento neste tipo de layout de espaço comercial por parte das marcas. Microsoft Word.

\section{Referências}

Damásio, A. (2004). Em busca de Espinosa: prazer e dor na ciência dos sentimentos. São Paulo: Companhia das Letras.

Raposo, D. A marca como ideal de vida. Publicado em Design Gráfico - Comunidade Brasileira de Design: http://designgrafico.art.br/comapalavra/marcaidealdevida.htm. Acesso em $13 / 04 / 2019$.

Gobé, M. (2002). A emoção das marcas: Conectando marcas às pessoas. Rio de Janeiro: Negócio.

Gurgel, M. (2010). Projetando espaços: guia de arquitetura de interiores para áreas comerciais. 3.ed. São Paulo: Senac.

lida, I. (2004). Tradução condensada do Capítulo 2 do livro Designing pleasurable products, de Patrick Jordan, Ed. Taylor \& Francis. London, 2000.Tradutor: Itiro lida. Brasília: set. 2004.

Jordan, P. W. (1995). Pleasure with products: Human factors for body, mind and soul. London. 
Teixeira, C.M.A. \& Mourthé, C.R. | O design e a comunicação afetiva no âmbito das lojas conceito: identidade, envolvimento e analogia entre as marcas e a sociedade de consumo atual

Jordan, P. W. (2000). Designing pleasurable products: an introduction to the new human factors. Taylor \& Francis.

Kurtgözü, A. (2003). From function to emotion: a critical essay on the history of design arguments. In: The Design Journal, V. 6, Issue 2.

Kotler, P. (2010). Administração de Marketing. 10. ed. São Paulo: Prentice Hall.

Lindstrom, M. B. (2012). Segredos sensoriais por trás das coisas que compramos. Porto Alegre: Bookman.

Menezes, C. S. (2007). Design \& emoção: sobre a relação das pessoas com os objetos usados pela primeira vez. Dissertação (Mestrado em Design), Rio de Janeiro: PUC-Rio.

Mont'alvão, C., \& Damazio, V. (2008). Design, Ergonomia, Emoção. Rio de Janeiro: Mauad X FEPERJ.

Nojima, V. L., \& Junior, L. A. (2010). Design, comunicação e semiótica. Rio de Janeiro: 2AB.

Norman, D. A. (2008) Design emocional: por que adoramos (ou detestamos) os objetos do diaa-dia. Rio de Janeiro: Rocco. Tradução de Ana Deiró.

Santos, F. A. (2012). Design: a conexão do corpo com o ambiente e a sintaxe do pensamento humano. Revista Tríades - Transversalidades, Design, Linguagens, 1(1), Rio de Janeiro: PUC-Rio.

\section{Sobre as autoras}

Celeste Maldonado Alves Teixeira, Esp., UFRJ, Brasil <celestemaldonado@globo.com> Claudia Rocha Mourthé, PhD, UFRJ, Brasil <claudiamourthe@gmail.com> 